\title{
Estudio formal, simbólico y estilístico de la Iglesia de Zaruma a través de su levantamiento fotogramétrico y relevamiento
}

\author{
Formal, Symbolic and Stylistic Study of the \\ Church of Zaruma \\ through its Photogrammetric Survey and \\ Rilievospaces
}

\section{Resumen}

Autores:

Jorge Romero-Galarza jpromero@pucesi.edu.ec

Pontificia Universidad Católica del Ecuador. Sede Ibarra (PUCESI)

Ecuador

Recibido: 05/Abr/2019 Aceptado: 17/Dic/2019 odos los monumentos patrimoniales de Ecuador deberían tener un registro formal, gráfico y fotográfico, textual e informativo, de cómo se originaron, cómo fueron construidos y cómo se encuentran en la actualidad. Para llegar a esto, es necesario llevar a cabo un levantamiento arquitectónico y un relevamiento de la edificación. Hay una gran diferencia entre estos dos conceptos: el levantamiento describe el aspecto físico del monumento a través de la toma de medidas, mientras que el relevamiento define los aspectos no materiales que ayudan a entender el origen de la edificación, la geometría y el porqué de las de las formas, la carga simbólica de sus componentes y los estilos involucrados. Este artículo da a conocer, a través del levantamiento y relevamiento arquitectónico como parte de la metodología de investigación, la forma, la geometría, las dimensiones, el origen, la simbología y los estilos de la Iglesia Matriz de la ciudad de Zaruma (Santuario de la Virgen del Carmen, ubicada en la parte alta de la provincia de El oro, Ecuador, cuya construcción data de 1912). Este registro será de mucha utilidad para la conservación y el restauro del bien patrimonial en caso de que sufra algún accidente o deterioro debido al tiempo, y así eventualmente ser recuperado en su forma original.

Palabras clave: levantamiento, relevamiento, conservación, patrimonio, simbolismo.

Abstract:

All patrimonial monuments of Ecuador should have a formal record both graphic and photographic, as well as textual and informative of how they originated and what their current state is. To achieve this, it is necessary to carry out an architectural survey and rilievo. There is a big difference between these two concepts: the survey describes the physical aspects of the monument, through the taking of measurements, while the rilievo defines the building non-material aspects that help to understand its origin, geometry, shapes, symbolism and styles involved. This article reveals, through the architectural survey and rilievo, as part of the research methodology, the shape, geometry, dimensions, origin, symbolism and styles of the Main Church of Zaruma (Sanctuary of the Virgen del Carmen, located in the upper part of the province of El Oro, Ecuador, whose construction dates from 1912). This record will be very useful for the conservation and restoration of the patrimonial good in the event of an accident or deterioration due to time, and thus eventually be recovered in its original form.

Keywords: survey, rilievo, preservation, heritage, symbolism. 


\section{Introducción}

La conservación de los monumentos arquitectónicos categorizados como patrimonio cultural intangible abre una nueva perspectiva en el campo de la investigación histórica de la arquitectura. Es importantísimo preservar el patrimonio edifica-do de cualquier ciudad en cualquier parte del mundo ya que la sustentabilidad en el tiempo del mismo se convierte en una fuente de identidad cultural. Considerando la importancia del registro y preservación de los bienes arquitectónicos para las naciones del mundo, no se puede descartar la relevancia del proceso de levantamiento y relevamiento arquitectónico, sobre todo en la ciudad de Zaruma, la cual ha ido ganando importancia desde su misma fundación; fue durante el corregimiento del Capitán Alonzo de Mercadillo que este fundó las tres ciudades de Loja, Zaruma y Zamora, a pesar de que su definitiva fundación fue realizada por el Capitán Damián de Meneses el 8 de Diciembre de 1595 (Poma, 1992, pp. 1420). Para esto hay que primeramente hacer un inventario de lo existente y de lo que se quiere perpetuar en el tiempo; es necesario luego no solo llevar a cabo un levantamiento arquitectónico, sino también un relevamiento global de los monumentos patrimoniales. La diferencia entre levantamiento y "relievo" (palabra de italiano "rilievo" para indicar este nuevo concepto) es bastante grande. El levantamiento es un proceso mecánico de medición y el segundo va más allá de la simple toma de medidas. El primero es un proceso de la geometría descriptiva que tiene como principal objetivo la representación de una manufactura, en la mayoría de los casos, arquitectónica, mientras que el segundo se refiere a varios procesos que responden al objetivo integral de conocer todo sobre ese edificio. Entonces, cuando se habla de relevamiento arquitectónico, se incluye también el estudio del pasado del edificio en cuestión, de sus intervenciones arquitectónicas, de sus características no solo formales, sino también funcionales e históricas. El objetivo particular de este artículo es entender, a través del levantamiento y relevamiento arquitectónicos, el origen, el porqué de las formas y los estilos de la iglesia que se conjugan para brindar un inigualable eclecticismo arquitectónico. Esto se lleva a cabo descubriendo y analizando no solo la geometría de sus formas, sino también la carga simbólica, tanto cristiana como numérica, detrás de esas formas encontradas en el monumento de estu-dio: la Iglesia Matriz, ubicada en el centro históri-co de la ciudad de Zaruma, provincia de EI Oro, Ecuador, del 1912.

Uno de los monumentos que mejor brinda la oportunidad de poner en práctica los conocimientos sobre levantamiento y relevamiento arquitectónicos es precisamente la Iglesia de Zaruma -el Santuario de la Virgen del Carmen.
Nuestro interés por conocer más sobre este monumento ha constituido el estímulo fundamental que nos ha impulsado a investigar, y as publicar en un futuro, una serie de artículos con una temática en común. Esta experiencia ha proporcionado destreza para plasmar las mismas técnicas de investigación arquitectónica a otros monumentos existentes en Ecuador, y en particular en este proyecto que ahora se está llevando a cabo sobre la Iglesia Matriz de la ciudad del cantón Zaruma - una bellísima localidad en la parte alta de la provincia de El Oro- que concluirá en un solo documento capaz de explicar el origen de la iglesia, su evolución y estado actual (Figura 1). Esta primera entrega se centra sobre las formas y la geometría en general, y la carga simbólicoestilística de algunos de los componentes de este monumento patrimonial (Docci y Maestri, 2009, pp. 23-54).

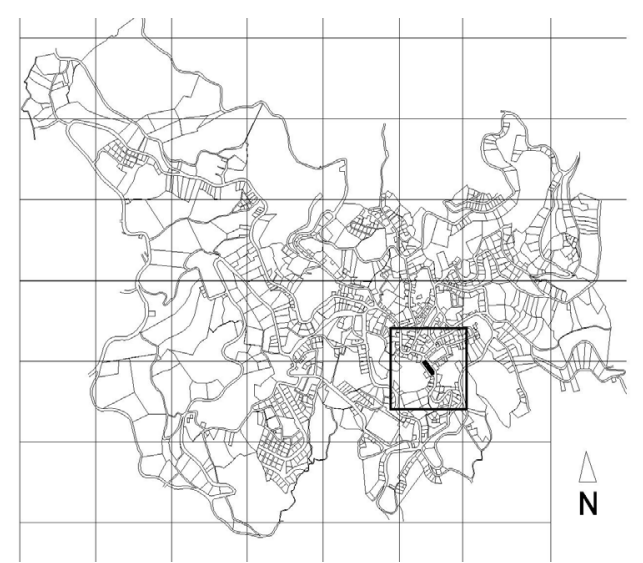

Figura 1: Ubicación de la Iglesia Matriz de Zaruma. Zaruma es una ciudad cuyo principal atractivo es su Centro Histórico, emplazado en una traza urbana que se desenvuelve sin patrones preestablecidos, con calles estrechas y empinadas, acompañadas de sorpresivas escalinatas para vencer a la pendiente (Aguirre, 2014, p. 41).

Fuente: Archivo catastral, 2018

\section{Metodología: métodos de relevamiento de recuperación} y proyecto de publicación final

El levantamiento arquitectónico de la Iglesia de Zaruma se llevó a cabo con la colaboración de un grupo de trabajo de ocho personas, de tal modo que fuesen cuatro grupos de trabajo de dos personas cada uno: dos grupos encargados de tomar las dimensiones (uno interior $y$ otro exterior) sosteniendo y usando las herramientas comunes de medición como flexómetros y altímetros, y los otros dos grupos, quienes acompañaban a los dos primeros respectivamente, encargados de registrar esas medidas. Se inició con copias de planos de época de la iglesia (elaborados por la compañía minera SADCO, 
South American Development Company), proporcionados por el Dr. Gonzalo Rodríguez, conocido historiador de la ciudad de Zaruma, para sobre ellos marcar, delimitar, sectorializar y distribuir las diversas áreas de intervención e incluirlas dentro de un cronograma de trabajo. De los varios métodos existentes de levantamiento arquitectónico, en este monumento en particular se utilizaron los siguientes:

El primer método de levantamiento, llamado "directo", se ejecutó con la ayuda de instrumentos de medición tradicionales, como flexómetros, cintas métricas, calibres, vernieres, micrómetros, etc. Existe toda una tecnología detrás del método directo que nos sugiere cómo usar las herramientas de medida casuales para lograr de estas la mayor precisión posible.

Después de medirlo todo (levantamiento planimétrico) se comprobaron las dimensiones por triangulación. Las alturas parciales y totales (levantamiento altimétrico), los espesores de ventanas, paredes y muros, etc., (levantamiento volumétrico) fueron tomados con la ayuda de instrumentos menos tradicionales y más tecnológicos, como teodolitos, micrómetros y altímetros digitales. Este segundo método, conocido como "indirecto", facilitó y aceleró la recolección de medidas y el grado de precisión fue mucho mayor que aquel obtenido con las herramientas convencionales. Este método, sin embargo, implica el uso de material de alquiler costoso, como e teodolito electrónico y digital (Bertocci y Bini, 2012, pp. 28-30).

Para bajar los costos presupuestales, se utilizó también un tercer método innovador conocido como "fotogramétrico", el cual hace uso de fotogramas de alta resolución captados con cámaras de lentes de alta calidad, tomados desde ciertos puntos de vista perspécticos, para luego, con la ayuda de un ordenador, enderezar las imágenes y convertirlas en fachadas con líneas de fuga paralelas, es decir, alzados totalmente perpendiculares al punto de vista. Se tomaron luego medidas parciales con longitudes representativas mayores a los dos metros y se usaron sobre los fotogramas. Luego se escalaron los fotogramas según esas medidas significativas y de esta forma se obtuvieron el resto de longitudes de todos los elementos del monumento arquitectónico a la misma escala (Genovese, 1994, pp. 120-125). No hay que olvidar en este punto, la importancia que tuvieron los primeros fotógrafos que registraron Zaruma con sus imágenes memorables: Ramón Jijón y León Jiménez Ramírez, entre otros más contemporáneos (Romero, 2011, pp. 27-33).

Este método fue extensamente utilizado - sobre todo en las fachadas - acelerando el levantamiento de pisos, fachadas, interiores y exteriores. Es aquí donde se encuentran los elementos con características de los órdenes clásicos de la antigüedad, como columnas (bases, fustes y capiteles), entablamentos (arquitrabes, frisos y cornisas), presentes en puertas y ventanas exteriores, tanto como en elementos estructurales interiores -incorporados en un estilo ecléctico predominante como reinterpretación del gótico, mudéjar y neogótico norteamericano en la Iglesia de Zaruma-, y sobre todo en áreas de difícil acceso, como la linterna octagonal que remata la torre-campanario (torre del reloj), también octagonal.
La fotogrametría fue una herramienta insuperable para la elaboración de levantamientos de detalles arquitectónicos internos - algunos de ellos en tallas de madera, en estucos de materiales calizos y en aluminio- como columnas, entablamentos, sofitos con paneles en talla de madera de formas barroquizantes, balaustradas que son representaciones reducidas y eclécticas de columnas de los órdenes clásicos griegos y romanos, y otros externos como ventanas y puertas con elementos decorativos en talla de madera, los cuales serían casi imposibles de registrar con el método directo o indirecto, a menos que el dibujante sea un artista de la interpretación y representación gráfica, como por ejemplo Giovanni Battista Piranesi. Este tercer método fue menos costoso que el segundo, a pesar de que se requirió equipo fotográfico de última generación y la ayuda de ordenadores y programas adecuados para la representación arquitectónica, como los CADs.

Desde un punto de vista organizacional, la información resultante de este proyecto de investigación fue dividida en tres fases: una primera parte textual que explica las características generales del objeto en estudio dentro de marcos teóricos específicos (componentes históricos y estilísticos del origen y de las formas del monumento patrimonial en estudio respectivamente), y que termina con varios aportes originales sobre los elementos constitutivos de la Iglesia de Zaruma y su carga simbólicoconceptual (Figura 2). Una segunda parte fotográfica, que sirve de sustento a todo el material textual, a base de imágenes monocromáticas de época y policromáticas del estado real de la iglesia; y una tercera parte gráfica, donde se muestran las representaciones resultantes del levantamiento y relevamiento arquitectónico, tanto material en tres niveles planimétrico, altimétrico y tridimensional (tipos de materiales, colores, estructuras, técnicas de construcción) como inmaterial (historia, origen, función, estilos y carga simbólica).

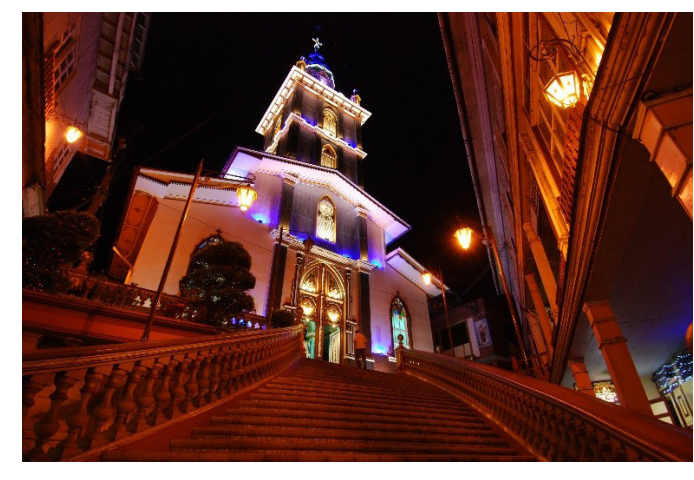

Figura 2: Fachada frontal de la iglesia con escalinata de acceso que conecta a la calle Bolívar.

Fuente: Propia, 2019

\section{Resultados y discusión}

Los resultados de la investigación, como se esperaba desde el inicio, evidenciaron con claridad las características eclécticas de la iglesia a través de la lectura de la geometría de las formas logradas con el levantamiento y relevamiento arquitectónicos de su totalidad y sus elementos constitutivos. 


\section{1 Órdenes y registros externos de la iglesia}

Para el entendimiento de las partes del diseño en alzado de la iglesia, se ha divido su altura total en secciones, denominadas órdenes. Existen cinco ordenes con subdivisiones llamadas registros en algunas de estas secciones. El primer orden cubre la distancia desde el piso hasta la altura de las naves laterales. Este primer orden se divide en cuatro registros: " $A$ " (base champeada de color café a modo de antepecho), "B" (muro liso de color claro donde se encuentran emplazadas las ventanas), " $C$ " (cornisa de remate de las naves laterales) y "D" (altura proyectada de la cubierta de las naves laterales). El segundo orden define la altura del claristorio, o sea, la distancia que va desde la cumbrera de las naves laterales hasta la cumbrera de la nave central. Este segundo orden tiene tres registros: "E" (muro liso de color claro donde se encuentran las bíforas del claristorio; "F" (falso friso decorativo), y "G" (altura proyectada de la cubierta de la nave central). El tercer orden abarca la distancia desde la cúspide de la nave central hasta el friso de la primera planta de la torre-campanario. Este tercer orden se divide en dos registros: " $\mathrm{H}$ " (muro con láminas de aluminio corrugado donde se emplazan las bíforas con ojiva), e "I" (cornisa que remata la primera planta de la torrecampanario). El cuarto orden se extiende verticalmente a lo largo de la segunda planta de la torre-campanario. Este cuarto orden también se divide en dos similares registros "J" (muro con láminas de aluminio corrugado donde se emplazan las cuadríforas ciegas con ojivas y los relojes de la torre-campanario), y " $\mathrm{K}$ " (friso-cornisa que remata la segunda planta de la torre-campanario). Finalmente, el quinto orden está ocupado por toda la altura de la linterna de la iglesia, que va desde el friso-cornisa de la segunda planta de la torre-campanario hasta la aguja de la linterna. Este último orden, a su vez, se subdivide en tres registros: "L" (altura proyectada del tramo piramida truncado de sección octagonal que va desde el frisocornisa de la segunda planta de la torre-campanario hasta el inicio del siguiente tramo), " $\mathrm{M}$ " (altura recta del tramo de sección octago-nal que va desde la cúspide de registro " $\mathrm{L}$ " hasta la base de la cúspide), y finalmente " $\mathrm{N}$ " (altura proyectada del tramo piramidal no truncado de sección octagonal que va desde la cúspide del registro " $M$ " hasta la aguja del pináculo de la linterna de la torrecampanario).

Como valores simbólicos importantes de todos los órdenes en su conjunto, se tienen los números cinco y tres. Cinco es el número de órdenes que tiene la iglesia y tres los elementos en que estos se descomponen. El número cinco es el resultado de la suma del primer número par más el primer número impar $(2+3)$, es el número de armonía y equilibrio y, además, es el número del centro. El cinco es también "el símbolo del universo: dos ejes, uno vertical y otro horizontal que pasan por el mismo centro" (Champeaux y Sterckx, 1980, pp. 243-44). Cinco es también el número de los sentidos y el número de la fortuna (riqueza, longevidad, paz, virtud y salud). Isidore Konsminsky hace una clasificación del valor simbólico del número cinco según las diferentes esferas a las que se refiere. Así, por ejemplo, en la esfera superior, lo que él quiere decir como ubicado a un nivel divino, el cinco indica las cinco letras del nombre de Dios; en la esfera del intelecto, el cinco indica los espíritus superiores, las inteligencias, los ángeles, las almas de los cuerpos celestes y las almas de los bienaventurados; y en la esfera infernal el cinco representa los tormentos (Konsminsky, 1998, pp. 26-27). El tres es universalmente un número fundamental. Expresa un orden intelectual y espiritual en Dios, en el cosmos y en el hombre. Sintetiza la triple unidad del ser vivo y resulta de la conjunción de uno y dos, producida por la unión del Cielo con la Tierra (Cairo, 2008, p. 67). Pero sobre todo el tres es el número de la gran tríada: el Hombre, el Cielo y la Tierra. El tres es el número perfecto por excelencia (omne trinum est perfectum). Las frases como "no hay dos sin tres" están inspiradas en este concepto (Chevalier, 1997, pp. 14546). Nosotros, hombres, contamos de uno a tres antes de comenzar cualquier actividad. Para los cristianos, el número tres es muy importante porque sintetiza el cumplimiento de la unidad divina: Dios es uno de cada tres personas. La Trinidad cristiana está compuesta por el Padre, el Hijo y el Espíritu Santo. En el mundo cristiano, el tres es uno de los números a los que se atribuyen el mayor número de virtudes. Para Cooper (2012), el tres es, de hecho, el número trinitario por excelencia; el tres también representa el alma y la unión del cuerpo con la mente en el Hombre y en la Iglesia. Tres son los regalos de los Reyes Magos al Niño Jesús, tres las cruces del Calvario, tres días de la muerte de Cristo y, finalmente, tres apariciones (Rees, 1994, p. 121).

Los números cinco y tres son muy importantes en la configuración arquitectónica de la iglesia de Zaruma por lo que se encuentran presentes tanto en su concepción básica arquitectónica como en la detallística a menor escala en sus fachadas, ventanas y portones (Figura 3). El tres, por representar la trinidad, se cuenta a lo ancho y a lo largo de la iglesia de Zaruma: tres son las naves y las divisiones de su fachada anterior, tres los pisos de la torre-campanario, así como los elementos atriforados de sus ventanas y otros elementos decorativos.

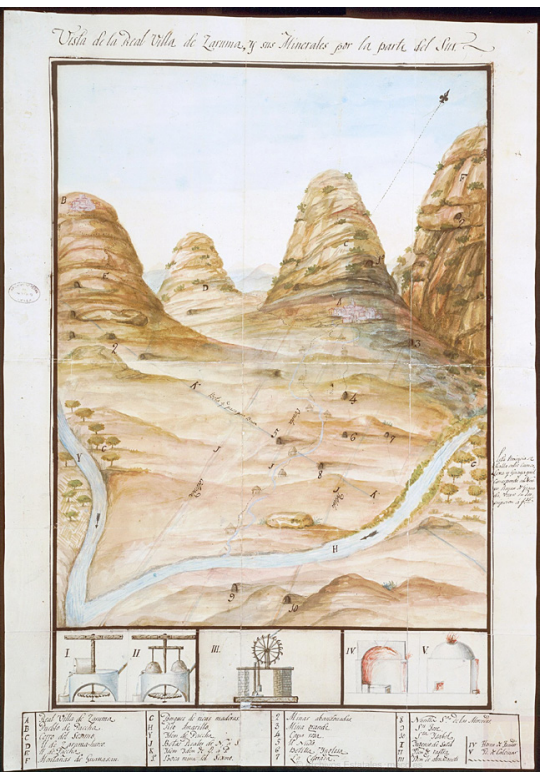

Figura 3: Representación gráfica, sacada del Archivo de Indias, de la Real Villa de Zaruma.

Fuente: Archivo General de Indias (Sevilla, España), dentro de la unidad Mapas, planos, documentos iconográficos y documentos especiales. Fecha de creación en 1817 


\section{Primer orden externo}

El primer orden externo está constituido por toda la tectónica de la primera planta que da la vuelta a la iglesia con una envolvente de características particulares. Este primer orden está dividido en cuatro registros: el primer registro "A" está formado por la altura que corre desde la línea de tierra hasta el inicio de las ventanas de las naves laterales, como si fuese un antepecho, de base champeada de color café; el segundo registro "B" está formado por el muro liso de color claro donde se encuentran emplazadas las ventanas de las naves laterales y constituye el registro principal del primer orden externo; el tercer registro " $C$ ", presente en la fachada lateral izquierda y no en esta fachada lateral derecha, debería estar formado por una cornisa que remata de la nave lateral, pero en este lado es inexistente; el cuarto registro "D" es la cubierta de las naves laterales o la altura proyectada en alzado de esta cubierta inclinada. Todos estos cuatro registros no giran alrededor de toda la envoltura de la iglesia de forma continua; de hecho, se interrumpen en la parte absidal de la iglesia, la cual precisamente tiene división de órdenes y registros propia para la fachada posterior de la iglesia (esta será explicada en la sección correspondiente sobre el lado posterior de la envolvente, a continuación).

En el primer orden externo hay varios números de importancia interpretativa. El número nueve, por ejemplo, es el número de ventanas de sus fachadas laterales, haciendo excepción en la fachada lateral izquierda, que tiene solo ocho, pero esto se explica por la presencia de portón lateral que reemplaza la ubicación de esta ventana. El nueve es el número de Juicio Final y de finalidad también. Este número también representa el fruto del Espíritu Santo. Jesús fue crucificado a las nueve de la mañana y murió a la hora novena del día. Hay nueve frutos del Espíritu (Gálatas 5:22-23) e indica la finalidad porque nada más es necesario. De igual manera, hay nueve dones espirituales (Corintios 12:8-10) (Ronchetti, 2004, p. 711). En cambio, el significado simbólico del número cuatro está vinculado geométricamente a la forma cuadrada y al número de lados del mismo, arquitectónicamente a la plaza y religiosamente a la cruz. Desde tiempos prehistóricos, el cuatro se utilizó para significar lo sólido, lo tangible, lo sensible. Su relación con la cruz lo convirtió en un símbolo incomparable de plenitud, de universalidad, un símbolo de totalización. La intersección de un meridiano y un paralelo divide la tierra en cuatro sectores. En todos los continentes, los jefes y los reyes son llamados: señores de los cuatro mares, o de los cuatro soles, o de las cuatro partes del mundo, etc. (Chevalier, 1997, p. 267). Este primer orden también tiene tres registros principales a nivel de muro vertical y un cuarto que es la cubierta; para cuestiones de simbolismo, el tres que es el número preponderante, ya que representa los registros verticales de la pared, y el cuarto registro cuenta de forma independiente como la caída proyectada de la cubierta que cubre la nave lateral. Otro número importante en este orden es el cuatro que son los lados en que se divide la fachada posterior de la iglesia o ábside, y ocho el número de ventanas que este orden contiene en su parte posterior, más dos del orden superior que da un total de diez. En la fachada anterior de este orden hay tres divisiones que se corresponden con las naves de la iglesia y tres elementos muy de importancia para la iglesia: dos ventanas laterales y el portón central. La importancia del valor simbólico del número cuatro se debe en gran parte a su presencia en la naturaleza. Cuatro son los puntos cardinales, cuatro vientos, cuatro pilares del universo, cuatro fases de la luna, cuatro estaciones, cuatro temperamentos, cuatro humores corporales (sanguis, flema, cólera y melancolía), cuatro direcciones del cielo, cuatro elementos de alquimia (tierra, fuego, agua y éter o aire), etc. De este modo el número cuatro está presente en la Iglesia de Zaruma en muchos de sus componentes y de su arquitectura misma. En la Biblia, cuatro es el número de los ríos de Paraíso (Fizón, Geón, Éufrates y Tigris) (Génesis 2, 10), y cuatro son las letras que forman el tetragrama del nombre de Dios (JHWH), Jahwèh, que a menudo se vocaliza. en "Jehová" (Cooper, 2012, p. 195). Para los cristianos, el cuatro es también el número del cuerpo, (Biedermann, 2004, p. 425) mientras que el tres es el número del alma Hay cuatro últimas cosas del cristianismo, a saber, los cuatro hechos escatológicos de la teología cristiana: la muerte, el juicio, el cielo y el infierno (Feuerstein, 2001, p. 76). La cruz tiene cuatro brazos. El tetramorfo está compuesto por los cuatro evangelistas: San Marco, San Giovanni, San Luca y San Mateo, que se corresponden con sus cuatro símbolos respectivamente: el león, el águila, el buey y el ángel. El número cuatro designa la plaza, y por lo tanto es un símbolo de lo terrenal y de la totalidad de la creación y de lo revelado.

\section{Segundo orden externo}

El segundo orden externo está constituido por toda la tectónica de la segunda planta que da la vuelta a la iglesia con una envolvente de características propias. Este segundo orden se divide en tres registros: " $E$ " " $F$ " $y$ " $G$ ". El registro " $E$ " es el muro liso de color claro donde se encuentran las bíforas del claristorio. Existen nueve ventanas abiforadas con un lado corredizo; cada falso batiente remata en alto con un arco ojival de características góticas. Cada lado de la bífora es un rectángulo que está formado por tres recuadros de vidrio con marcos de madera. Los dos últimos recuadros en alto inscriben sendas ojivas de madera con vidrio al interior de las mismas. Entre las dos ojivas existe una pequeña decoración floral cuadripartita. Todas las nueve ventanas se corresponden con las bajo estantes a través de sus correspondientes ejes de simetría. En el lado anterior de este segundo registro, bajo la torre-campanario, existe una ventana rectangular con 25 lamas de madera a modo de persiana; el diseño de esta ventana es más simple y menos elaborado que aquel de su contraparte en el segundo registro de la fachada lateral izquierda. El registro " $F$ " es un falso friso decorativo, falso porque está simplemente resaltado con dos líneas de color más obscuro que el muro mismo, una línea inferior y otra superior de similar espesor que la anterior y que juntas definen este friso no tridimensional. El registro " $G$ " es la altura proyectada de la cubierta de la nave central. Este tercer registro está cubierto por una techumbre de tejas sobremontadas de terracota.

En el segundo orden externo hay varios números de importancia interpretativa, igualmente que en el primero. El diez es el número de ventanas en sus fachadas laterales, nueve del mismo tipo y sendas ventanas 
individuales diferentes en la parte anterior de cada fachada lateral. Así, cada lado del claristorio tiene un total de diez ventanas. En el cristianismo, diez es e número de los Mandamientos del Decálogo; diez son las parábolas de las diez lámparas, de las diez vírgenes, de los diez talentos; los diezmos debían ser entregados a Dios (Cooper, 2012, p. 200). Tanto para los cristianos como para los pitagóricos, diez es el número perfecto; contiene al mismo tiempo lo bueno y lo malo, lo par y lo impar, lo móvil y lo inamovible; contiene el poder activo de todos los números; es el principio de toda vida y de toda inteligencia. Representa la vida divina y el ser en su perfección, porque no es solo la suma de diez unidades, sino también la unidad de esta suma (Mallinger, 2008, p. 153). En este segundo registro hay dos ventanas en el ábside de la iglesia. El dos es también un número muy importante para el cristianismo. Aparte de valor simbólico bíblico del número dos (Adán y Eva), los dos son un símbolo de toda dualidad, concepto dicotómico u oposición. Es el número de todas las ambivalencias y las duplicaciones, a partir de la primera y más radical de las divisiones: el creador y la criatura, el blanco y el negro, el bien y el mal, el masculino y el femenino, la materia y el espíritu, día y noche, vida y muerte, hombre y animal, cielo y tierra, Dios y el diablo, arriba y abajo, sol y luna, etc. Puede ser que la tendencia a ordenar en pares de opuestos complementarios esté conectada al hecho de que el hombre mismo está compuesto de dos partes: una buena y una mala, o incluso la diferencia física primordial entre un hombre y una mujer. Asimismo, en la arquitectura de la Iglesia de Zaruma este número es una constante en todos los ámbitos: ventanas divididas en dos batientes, bíforas con características góticas, dos lados de ventadas del claristorio, dos aguas para cada techumbre, dos ingresos principales, dos ventanas frontales principales, etc.

\section{Tercer orden externo}

El tercer orden externo está constituido por toda la tectónica que da la vuelta y a la vez recubre la primera planta de la torre-campanario. El lado derecho de la envolvente (fachada lateral derecha de la primera planta de la torre-campanario) tiene la misma altura externa que aquella de su contraparte (fachada lateral izquierda de la primera planta de la torrre-campanario). Esta altura está medida desde la intersección entre el plano inclinado de la techumbre y el plano vertical de la torrecampanario (el arranque de la torre) hasta el inicio de la cornisa perteneciente a este mismo orden. Este lado tiene cuatro pilastras equidistantes que dejan tres espacios entre ellas de iguales dimensiones (ancho y altura). El espacio interpilastral central contiene una ventana a único batiente con cuatro parteluces equidistantes que rematan cada uno de ellos en una pequeña forma de pirámide invertida, como si fuese un pequeño capitel. E batiente rectangular es una celosía de tipo veneciana con 25 lamas de persiana enmarcadas en la estructura de batiente (dos largueros laterales y travesaños inferior $y$ superior). Esta ventana es abisagrada en su lado derecho y se abre hacia el interior de la torre-campanario. La ventana está coronada con un diseño geométrico modular a base de nueve arcos ojivales; La base de la ojiva principal (u ojiva primaria por su mayor tamaño), cubre todo el ancho de la ventana y remata en la parte superior donde sus lados se juntan; de este punto descien- den dos pequeñas ojivas más (ojivas secundarias) que se pierden al intersecarse con el círculo de rosetón. De la base de la ojiva principal nacen dos ojivas (ojivas terciarias) hacia arriba, y éstas a su vez se subdividen en dos pequeñas ojivas más (ojivas cuaternarias). El círculo de rosetón inscribe una forma cuadripartita a base de la intersección de cuatro círculos, de cuyo centro geométrico divergen cuatro lirios afrontados diagonalmente de dos en dos. El fondo del rosetón es un plafón de madera de color blanco, mientras que el fondo de la ojiva primaria está compuesto, como el batiente de la ventana, de una persiana a base lamas de madera. Toda la ventana, que en realidad es una falsa bífora, ya que tiene un solo batiente pero formalmente da la impresión de estar compuesta por dos batientes que rematan en dos ojivas, está construida enteramente de madera. Los cuatro lados de la torre-campanario tienen una estructura interna de madera; sin embargo, las paredes están recubiertas externamente por una sucesión de láminas de aluminio corrugado, que dan a la torre su característica propia, además de protegerla de las inclemencias del tiempo. Esta ventana encuentra su correspondiente contraparte en el lado opuesto (fachada lateral izquierda de la primera planta de la torre-campanario) de características y diseño similares.

Este tercer orden se divide en dos registros " $\mathrm{H}$ " (muro con láminas de aluminio corrugado donde se emplazan las bíforas con ojiva) e "I" (cornisa que remata la primera planta de la torre-campanario). El registro " $\mathrm{H}$ " cubre la altura desde el arranque de la torre-campanario hasta el inicio o la base de la cornisa correspondiente.

\section{Cuarto orden externo}

El cuarto orden externo está constituido por los cuatro muros, estructurados en madera y recubiertos de láminas de aluminio corrugado, que giran en torno a la segunda planta de la torre-campanario. El lado derecho de la envolvente (fachada lateral derecha de la segunda planta de la torre-campanario) arranca desde el cubreaguas de la cornisa del tercer orden externo y termina en el cubreaguas que remata la cornisa de este cuarto orden externo. El muro es la continuación estética tectónica del inicio de la torre-campanario; es decir, tiene cuatro pilastras equidistantes que dejan tres espacios entre ellas de iguales dimensiones (ancho y altura). El espacio interpilastral central, al igual que en el orden inferior, se caracteriza por un elemento jerárquico que, en este caso, al contrario que en el orden inferior, no es una ventana sino un reloj que se enmarca en lo que podría ser una ventana ciega con características formales de la simplicidad del gótico americano. El reloj está decorado en su parte superior por una ojiva que desde su punto de intersección superior se subdivide en dos arcos; los dos lados del arco ojival terminan en la parte inferior en una gota del gótico flamígero que mira hacia abajo, envés de hacia arriba. El reloj, en su parte inferior, descansa sobre dos bíforas, formando así una cuadrífora. El remate superior de cada bífora tiene forma cuasi-romboidal con decoración floral al interno. Las dos flores de las dos bíforas son de color blanco enmarcadas en una forma a cuatro hojas de color café, que constituye el perímetro del cuadrifolio. Entre las dos bíforas existe un elemento decorativo de forma cuasi-triangular con lados curvos: este debe ser más bien considerado como parte de 
remate inferior del reloj y no como un elemento que descansa sobre las dos bíforas bajo estantes. La base de las dos bíforas está formada por cuatro recuadros de iguales dimensiones, que inscriben cuatro cuadrifolios con las mismas características que aquellos que coronan las bíforas, pero ligeramente a una escala proporcionalmente mayor. Estos cuatro recuadros están sormontados, cada uno de ellos, por dos llamas encendidas, haciendo un total de ocho puntas de velas que iluminan y señalan el reloj de forma simbólica. Los elementos verticales de las dos bíforas contienen en su parte superior la típica decoración flamígera afrentada hacia el interior de cada una de las cuadríforas. El perímetro del reloj está formado por una circunferencia angosta de fondo blanco que contrasta con los 57 puntos en alto relieve de color café que la decoran. Todos estos dos elementos decorativos están tallados en madera con la bicromía característica del externo de los diferentes órdenes y registros de la iglesia: blanco y café.

Este cuarto orden también se divide en dos similares registros "J" (el muro con láminas de aluminio corrugado donde se emplazan los relojes también con cuadríforas ciegas) y "K" (el friso-cornisa que remata la segunda planta de la torre-campanario). El registro "J" cubre la altura desde el arranque del cuarto orden hasta el inicio - la base de la cornisa correspondiente. Este registro es aquel que, como ya se explicó, está recubierto por láminas de aluminio con pilastras del mismo material y contiene los relojes de la torre-campanario.

El número simbólico que domina los órdenes tercero y cuarto es precisamente el cuatro, del cual ya se ha explicado su significancia. Cuatro son los lados de la torre-campanario en sus dos pisos, cuatro las ventanas, de cada orden, que miran hacia los cuatro puntos cardinales. Cada orden se subdivide en tres partes verticales, y en dos y tres registros respectivamente. El cuatro es un numero par, así como el dos, y está fuertemente vinculado en la arquitectura de toda la iglesia, no solo en alzados - los registros que son la materia de esta investigación - sino también en la mayoría de sus plantas que tienen formas cuadrangulares vinculadas con el cuatro. Las plantas del tercer y cuarto orden de la torrecampanario son cuadradas. El cuadrado es símbolo de lo terrestre y el círculo, como contraposición, es símbolo de lo celestial. Como se ha dicho, "el cuadrado es una de las figuras geométricas más frecuentes y universalmente utilizadas en el lenguaje de los símbolos. Es uno de los cuatro símbolos fundamentales, junto con el centro, el círculo y la cruz" (Chevalier, 1997, p. 257). El cuadrado recuerda todo lo que pertenece al mundo terrestre, y más específicamente a la tierra. Además, es el símbolo del universo creado, en oposición al símbolo del Creador, el círculo. El simbolismo del cuadrado está vinculado al del número cuatro, cuya forma y número están presentes a lo largo y ancho de la Iglesia de Zaruma.

\section{Quinto orden externo}

El quinto orden externo está constituido por la linterna de sección octagonal desde su arranque al nivel del frisocornisa del cuarto orden externo (segunda planta de la torre-campanario) hasta el pináculo rematado por la cruz cristiana mirando hacia noroeste. Toda esta estructura interna de madera está cubierta por láminas de aluminio, pero esta vez, no corrugado.
Este último orden se subdivide en tres registros: " $\mathrm{L}$ " (altura proyectada del tramo piramidal truncado de sección octagonal que va desde el friso-cornisa de la segunda planta de la torre-campanario hasta el inicio del siguiente tramo), " $\mathrm{M}$ " (altura recta del tramo de sección octagonal que va desde la cúspide del registro "L" hasta la base del pináculo) y finalmente " $\mathrm{N}$ " (altura proyectada del tramo piramidal no truncado de sección octagonal que va desde la cúspide del registro "M" hasta la aguja del pináculo de la linterna de la torre-campanario. Todos los ocho lados de la linterna comparten características formales y decorativas similares alternas en algunos casos.

Para los cristianos, ocho es el número de regeneración, de renacimiento (Cooper, 2012, p. 199). La pila bautismal y el baptisterio son octagonales porque simbolizan un lugar de regeneración. El octavo día viene después de los seis días de la creación más el sábado. Ocho es el número que anuncia la futura era eterna, indica no solo la resurrección de Cristo, sino también la del hombre. Si el número siete se manifiesta como el número por excelencia del Antiguo Testamento, el ocho corresponde al Nuevo Testamento. Después del séptimo día, llega el octavo, que marca la gloria de los justos y la condena de los malvados. El octavo día es el símbolo de la transfiguración, de la resurrección de Cristo y de la promesa de la resurrección del hombre renovada por la gracia (Chevalier, 1997, p. 176). Ocho es el número de la resurrección porque tuvo lugar el octavo día (Ronchetti, 2004, p. 697). Ocho es el número de lados de los baptisterios y la fuente bautismal de la Iglesia de Zaruma no es la excepción.

\section{Ventanas}

La geometría de las formas de las ventanas de la Iglesia de Zaruma se basa en la repetición, en el desdoblamiento y sobre todo en el concepto de afrontamiento, ya que muchas de sus formas son especulares, con un eje de simetría que, en la mayoría de los casos, es vertical. Sus diseños se basan en formas básicas con fuerte carga simbólica, no solo de carácter cristiano sino también universal, como el cuadrado, el rectángulo, el triángulo y el círculo, las cuales al combinarse dan lugar a un sincretismo formal de carácter ecléctico; sin embargo, es el círculo y sus derivados que predominan en las ventanas de mayor complejidad conceptual y elaborativa. Esta "figura plana correspondiente a los lugares de los puntos, cuya distancia desde el centro es menor que la distancia conocida como radio" (Redazione Garzanti, 2013, p. 372) es el símbolo geométrico más importante y más extendido. Esta interminable sucesión de puntos está presente desde el origen en la naturaleza misma. Así, la imagen del sol y la luna tienen esta forma determinada. El símbolo del círculo se refiere al culto solar de los primitivos $\mathrm{O}$, en las religiones modernas, a los mitos, a los motivos del mandala de los monjes tibetanos, y siempre indica el aspecto esencial de la vida, su globalidad total y definitiva (Jung, 1991, p. 225). El motivo del círculo como símbolo celestial también es muy antiguo, y no pertenece, como hemos visto antes, solo a la tradición cristiana, ya que fusiona un ideal decorativo de belleza formal con una especulación cósmica (Klange, 2001, p. 248). El círculo, además, siempre ha sido considerado como la figura perfecta (según la filosofía platónica) y representa la perfección. El movimiento circular es per- 
fecto, inmutable, sin principio ni fin, ni variaciones. y por estas mismas características es también un símbolo genérico del tiempo, de la eternidad y de la inmortalidad (Cecchini, 1998, p. 455). El círculo también puede representar el cielo, desde el movimiento circular e inalterable. De acuerdo con los textos de los filósofos y teólogos, e círculo es un símbolo de la divinidad considerado como inmutable y lleno de bondad como el origen de todas las cosas, así como el punto es, en cambio, el origen de las diferentes figuras geométricas. En palabras de Chevalier: "El círculo es, ante todo, un punto extendido y participa en su perfección. Por lo tanto, el punto y el círculo tienen propiedades simbólicas comunes: perfección, homogeneidad, ausencia de distinción o división" (1997, p. 245).

En Arquitectura el término "afrontamiento" se refiere a las figuras, especialmente de animales, colocados simétricamente uno frente al otro. Conceptualmente, "afrontamiento" es un término opuesto al de "adosamiento", este último indica, en cambio, las figuras colocadas espalda con espalda, principalmente animales en capiteles, pilares y otros elementos arquitectónicos. Casi todos los monumentos religiosos tienen, como parte de su decoración externa e interna, una serie de figuras enfrentadas entre sí o, en cualquier caso, pares de imágenes que quieren representar no solo el contraste entre el bien y el mal, sino también otros conceptos dicotómicos, como por ejemplo el alma y el cuerpo, Cristo y su Iglesia o Caín y Abel. Especialmente en el arte religioso es muy común encontrar la representación de estas dicotomías bíblicas en forma de parejas enfrentadas de animales dispares como leones, dragones, grifos o serpientes (Beigbeder, 2009, p. 213). La Iglesia de Zaruma no es la excepción. El desarrollo de imágenes fitoformes, zooformes o simplemente geométricas u orgánicas, al interno de la decoración de las ventanas y de otros elementos de fachadas y del interior mismo de la iglesia, se encentra en posición de afrontamiento. El desarrollo mismo de su geometría general de las formas presentes en la decoración de las ventanas se basa en este concepto primordial de la arquitectura fuertemente vinculado al de cristiandad: desarrollo de formas decorativas cara con cara.

\section{Portones}

La puerta es, per sé, uno de los elementos más importantes de la envolvente exterior de la Iglesia de Zaruma tanto como función y sobre todo como contenido, y, por tanto, tiene su propia simbología. En la tradición judeocristiana, la importancia de la puerta es inmensa, ya que da acceso a la revelación. Las armonías del universo se reflejan en ella. Las puertas del Antiguo Testamento y del Apocalipsis son las del majestuoso Cristo y las del Juicio Final, que dan la bienvenida a los peregrinos y fieles (Chevalier, 1997, p. 241). Según San Clemente de Alejandría, citando las Sagradas Escrituras, Cristo mismo es la puerta de la justicia: "Ábreme las puertas de la justicia: vendré a dar gracias al Señor: esta es la puerta del Señor, porque vienen los justos" (Salmos 118, 19-20). La historia de Sansón que socava las puertas de la puerta del templo de los filisteos de Gaza se interpreta como un modelo tipológico de la obra salvadora de Cristo. "Sansón descansó hasta la medianoche, y a la medianoche se levantó, agarró las aldabas de las puertas de la ciudad y las dos jambas, dividiéndolas juntas con la barra, las puso sobre sus hombros y las llevó a la cima de la montaña mirando en dirección a Hebrón" (Jueces 16, 3). Desde el momento en que a los cristianos se les permitió construir iglesias libremente, atribuyeron mucha importancia a la decoración de las puertas. Los transformaron en una invitación a entrar, de acuerdo con la palabra de Cristo que se había comparado con una puerta (Juan 10, 1-21) (Cooper, 2012, p. 236). Los portales de monumentos cristianos a menudo están decorados con representaciones de los deberes que deben cumplirse; de hecho, representan tanto las virtudes cristianas como los vicios contra los cuales deben luchar las virtudes. En los cuadrantes de los portales, a menudo se representa al glorioso Cristo porque él mis-mo, a través del misterio de la Redención, es la puerta a través de la cual se accede al Reino de los Cielos. Los guardianes de las puertas celestiales son el arcángel Miguel o el apóstol Pedro, que posee las Ilaves (Urech, 2001, p. 212). Las tres puertas de una iglesia generalmente simbolizan la fe, la esperanza y la caridad. La iglesia de Zaruma tiene dos portales principales y una puerta menor en la parte posterior, como ingreso de las autoridades eclesiásticas.

\subsection{Síntesis}

La iglesia Matriz de Zaruma no tiene una orientación norte sur, sino una orientación que responde a las necesidades de implantación según la topografía compleja de la ciudad y la presencia de la Plaza de la Independencia. La longitud de la planta basilical a tres naves (una central con claristorio y dos laterales de menor ancho y altura) tiene su eje de orientación noroeste-sureste con la fachada anterior de ingreso principal que se abre hacia las escalinatas mirando hacia el noroeste, correspondientemente con la orientación de la cruz latina que remata su cúspide. La calle principal de la ciudad (calle Bolívar) se abre en una curva que es el acceso a las escalinatas del ingreso principal anterior de la iglesia. El ingreso lateral, tan o igual de importante que el anterior, se abre hacia la plaza principal de la ciudad. La ubicación de la iglesia tiene una orientación estratégica perpendicular a la plaza principal con dos portones, uno hacia el noroeste para recibir a los peatones desde la calle principal de la ciudad y otro para comunicar con la plaza donde se celebran todo tipo de eventos públicos, hacia el noreste. El eje de asoleamiento este-oeste, con su variación de 23 grados en los solsticios, ilumina el ábside de la iglesia desde levante, y la fachada anterior principal desde poniente. La sombra proyectada de la torre-campanario recorre la cubierta de la iglesia desde oeste a este de forma particular. Durante las mañanas, protege a los feligreses que suben por la escalinata principal y por la tarde protege del sol a los que ingresan por el portón lateral (Figura 4). El cuerpo mismo de la iglesia da sombra a poniente y levante según las horas de transcurso solar durante el día.

El primer orden externo tiene ventanas de carácter góticoflamígero, con arcos ojivales formando falsas bíforas que rematan tanto en su parte inferior, con elementos florales, y en su parte superior, con lirios abiertos hacia el cielo. Existen también elementos clásicos en lo que se refiere a los capiteles que decoran las ventanas. La geometría resuelve las ventanas con pares de ojivas afrontadas y cuadrifolios de remate superior. El portón 


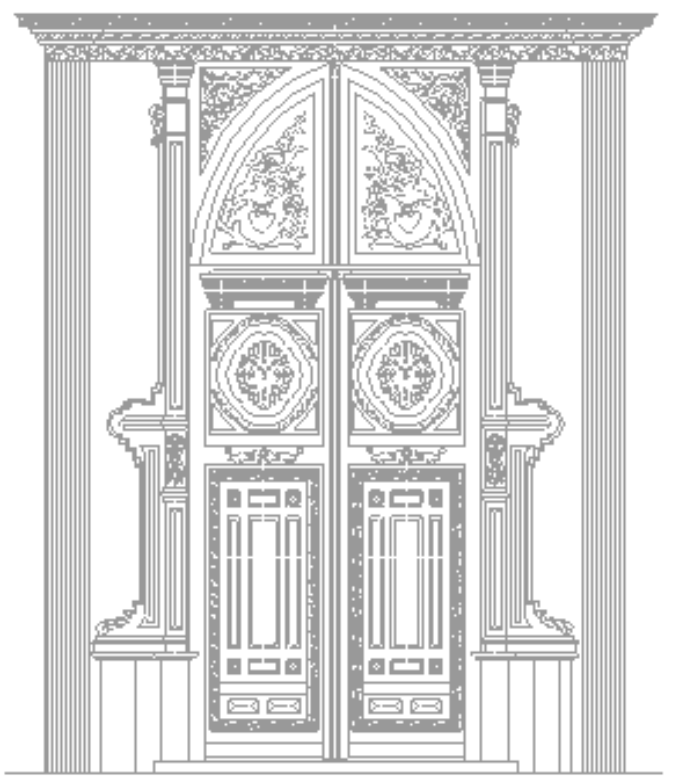

Figura 4: Levantamiento fotogramétrico del portón lateral.

Fuente: Elaboración propia con la ayuda de estudiantes universitarios, 2016

lateral, igualmente, tiene decoración clásica estilizada y decoración fitoforme geometrizada. Rosetones, grecas, corazones ardientes, decoran el portón lateral, además de pilastras con pedestales, bases, fustos, y capiteles de reminiscencia clasicista que encuadran este portón lateral. El alto, en cambio, de este primer orden está ornamentado por frisos con componentes clásicos y componente estilizados y simplificados. El portón y ventanas de la fachada anterior siguen las mismas características eclécticas de la fachada lateral.

El segundo orden externo es menos complejo que e primero. El primero tiene una decoración en talla en madera mucho más elaborada. El segundo orden se convierte en la versión simplificad del primero; se mantiene las formas abiforadas del gótico, pero tienden a un gótico americano, mientras que las del primer orden son más comunes en el gótico europeo. En otras palabras, las fachadas que cubren las naves laterales del primer orden externo tienen un diseño y una decoración preponderante en relación a las fachadas que cubren e claristorio de la nave central. Es evidente que se jerarquizó este orden priorizándolo sobre el segundo por razones de exposición visual a los peatones que ingresan por los portones mirando las ventanas, las cuales, con su mayor área, dejan pasar gran cantidad de luz para iluminar tanto las naves laterales como la nave central.

La torre campanario en sus tres órdenes (tercero, cuarto y quinto) dejan entrever la influencia del gótico en su versión americana más estilizada, lineal y simplificada. La fusión ecléctica de materialidad en la tectónica del cuerpo de la iglesia con aquella de la torre-campanario crea una simbiosis única, propia de la habilidad y creatividad de los artistas locales, la cual se refleja también en las construcciones residenciales de la ciudad. Todas estas ideas a modo de síntesis no habrían sido posibles sin un relavamiento, además del levantamiento, basado en un conocimiento sobre la evolución de las intervenciones de la iglesia, desde los inicios de su construcción misma, que estuvo dirigida por el sacerdote zarumeño Dr. Manuel Jacinto Chiriboga Romero, y que se inició el 21 de Julio de 1912 y se terminó el 1 de Marzo 1930, como lo indica la placa conmemorativa ubicada en el lado izquierdo inferior de la fachada anterior de la iglesia, con el nombre de su maestro mayor, de origen lojano, Carlos Ruiz Burneo, hasta las múltiples restauraciones del interior realizadas por en el pintor Marco Tulio Gallardo, quien realizó con óleos escenas del Antiguo y Nuevo Testamentos (Reyes, 2011, pp. 27-33).

\section{Conclusiones}

La arquitectura de la iglesia es evidentemente una mezcla de estilos, pero sobre todo podemos evidenciar la presencia del gótico flamígero, con sus elementos en talla de madera y formas de llamas y velas encendidas que rematan las ventanas inferiores y otros elementos de la torrecampanario. La influencia de elementos de la antigüedad clásica griega es también evidente en sus fachadas principales, donde se ubican ventanas y portones. Las cornisas y frisos-cornisas están conformadas por bandas canónicas reinterpretadas localmente. Grecas romanas sirven también de inspiración para decorar ventanas y rematar los dos primeros ordenes externos. La geometrización decorativa de elementos góticos y clásicos muestran la influencia del arte islámico, más puntualmente mozárabe, sobre ventanas, frisos y cornisas, pero sobre todo en el interior de la iglesia, donde esta influencia es mucho más notoria. En términos estrictos podemos concluir que la iglesia tiene características neoclásicas, neogóticas, arabescas. El neogótico norteamericano también deja su huella sobre nuestra iglesia como lo evidencian las per-sianas de madera con características decorativas del gótico estilizado, y el pináculo octagonal que remata la torre campanario. La materialidad de la iglesia (madera, aluminio, tejas, bahareques, estucos, entre otros) son el resultado del uso de los recursos locales. Esta simbiosis de materiales autóctonos ha dado lugar a una nueva conceptualidad constructivo-arquitectónica que se puede ver solo en la parte alta de la provincia de El Oro y específicamente en la ciudad de Zaruma. Hoy por hoy, esta tipología constructiva es la carta de presentación de esta ciudad cultural, la cual se ve reflejada no solo a través de sus edificaciones principales de carácter religioso, sino también a través de sus residencias igualmente catalogadas como patrimonio arquitectico y cultural.

La carga simbólica de la decoración externa es muy extensa, pero se podría resumir a través sus componentes de carácter cristiano, como los corazones ardientes de Jesús sobre los dos portones anterior y lateral, las cruces latinas que rematan algunos de los elementos de puertas y ventanas, las llamas estilizadas que representan no solo el sufrimiento de Cristo, sino también la llama que ilumina la humanidad con la presencia de cristo, las velas encendidas que evocan la iniciación a la lectura de la Biblia y como ésta nos guía y nos ilumina a través del camino obscuro sin no andamos de la mano de Dios, los ángeles que cuelgan de las falsas bíforas del primer orden externo que representan el Espirito Santo que desciende y mira hacia la tierra para llevar la buena nueva como vínculo entre lo celestial y divino con lo terrestre y mundano. 
La decoración fitoforme recuerda la presencia de la naturaleza en la vida de los seres humanos, y la importancia que ésta tiene en los quehaceres diarios de la mano del Señor. Flores como lirios, símbolos de pureza y rectitud, se manifiestan en puertas y ventanas. Plantas y composiciones geometrizadas de plantas también tienen un objetivo similar y son la representación del paraíso terrenal. Ramos de uvas, sin cornucopias, simbolizan la abundancia terrenal que todos los hijos de Dios se merecen. Pantas y lirios afrontados representan la dualidad entre mundo celestial y terrenal. Pequeños serafines sobre nubes cuelgan de las falsas bíforas externas de primer orden.

La simbología de los números también está presente a lo largo y ancho de toda la iglesia. El tres representa la trinidad; tres son las naves de la iglesia y las divisiones de los portales, tres son las divisiones de las tríforas internas de las ventanas del primer orden externo. Las triforas internas del primer orden externo están diseñadas en base a la geometría del número tres y sus múltiplos: tres arcos ojivales y seis mitades de arco. La fachada principal está dividida en tres partes que demarcan las tres naves. La torre-campanario tiene tres registros. El número tres se repite en los diferentes registros externos a nivel de decoración. Este número es uno de los más importantes en la simbología cristiana. El número dos y sus múltiplos también son de gran relevancia en el diseño decorativos de los registros externos. El dos representa la dualidad entre el cielo y la tierra. Dos son los arcos ojivales de las bíforas y cuatro son los pétalos de los cuadrifolios. Dos son los pétalos de los lirios que se abren hacia el cielo y cuatro son los lados de la cruz latina. Dos son los componentes afrontados fitoformes y floriformes, y cuatro son las divisiones horizontales de las ventanas del primer orden externo. Cuatro son las partes principales en las que se dividen los rosetones y madera, y doce las divisiones de los mismos. El doce representa el número de los apóstoles. El ocho representa el octavo día después de los siete de la semana y esto indica la eternidad divina, la creación y el infinito. Ocho son los lados de la linterna de la torre-campanario y el número base de elementos decorativos del exterior de la iglesia. Nueve es el número de las ventanas del primer y segundo orden externo. Los números dos, cuatro, tres, seis, nueve y doce son los que se repiten constantemente, tanto en sistemas estructurales, divisiones y sobre todo en elementos decorativos con una fuerte carga de simbolismo y significancia religiosa.

Los colores más significativos del exterior de la iglesia son el blanco, el dorado y el café en dos tonalidades, claro y obscuro. Prevalece la bicromía en alternancia para crear un ambiente de poco contraste y una paleta limitada de colores. El rosa pálido, casi blanco, también juega un papel preponderante, sobre todo en grandes superficies como aquellas de la fachada principal y de las fachadas laterales. El color plata marca la diferencia con el cuerpo de la iglesia para resaltar la torre-campanario. En definitiva, los materiales de la torre campanario son de color plata; los tallados de madera son generalmente bícromos, contrastando en blanco con el café obscuro, y el rosa pálido en superficies verticales. El dorado no juega un papel muy importante en el externo de la iglesia, pero sí en el interno, así como el azul obscuro y celeste. Hay que recalcar que el exterior de la iglesia es muy diferente al interior, tanto en materiales, colores y decoración. En un artículo posterior se tratará sobre el levantamiento del interno de la iglesia con sus detalles y particularidades, así como se lo ha hecho en esta publicación en lo referente al externo. A pesar que la simbología de los colores no fue parte del propósito de esta investigación, cabe indicar que esta también es representativa en la arquitectura de la Cristiandad, y también en la Iglesia de Zaruma. Por esta razón también se hizo un breve recuento de la paleta de colores presente en este monumento del patrimonio zarumeño, orense y ecuatoriano. 


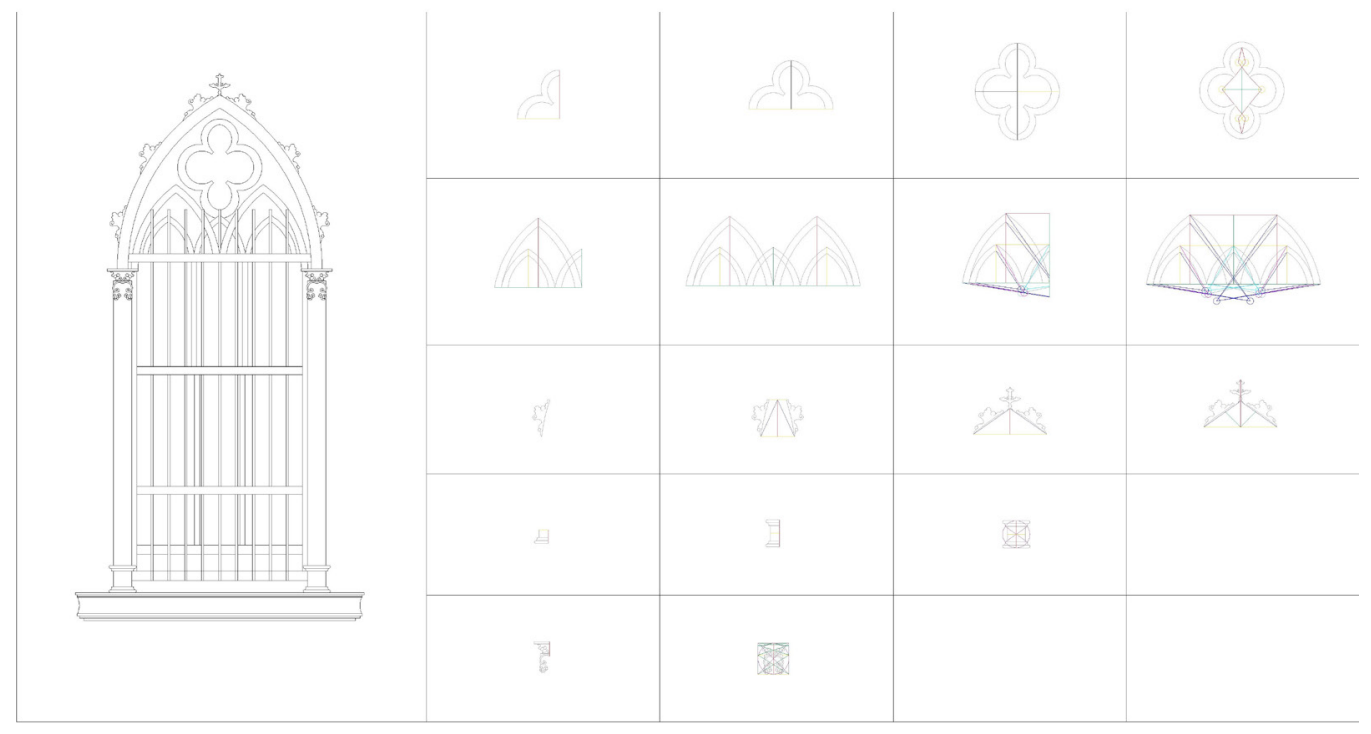

Anexo 1: Desarrollo geométrico de las formas existentes en los componentes de la ventana tipo 1. En el primer caso existen dos ejes de simetría vertical y horizontal (rojo y amarillo), lo que permite descomponer al cuadrifolio en cuatro partes no idénticas. La especularidad se da en sentido vertical y luego en sentido horizontal, pero no en sentido transversal; es decir, las formas son idénticas de dos en dos en sentido vertical y horizontal. Existen seis puntos de centros de círculos por lo que las resultantes no son circunferencias perfectas, pero sí segmentos de arcos. En el segundo caso existen tres ejes verticales de desdoblamientos simétricos; el primero (rojo) da lugar al arco ojival principal y más grande; el segundo (amarillo) da lugar al arco ojival menor lateral no alineado con el anterior; los ejes rojo y amarillo tienen un desfase de pocos centímetros entre ellos, con el objetivo de lateralizar el arco menor. El tercero y último (verde) es el eje de simetría vertical a través del cual la composición geométrico-formal queda completada. Aquí se manejan diez puntos de cetro de arcos que dan lugar a las formas de las diferentes ojivas góticas. En el tercer caso es más bien orgánica fitoforme. La distancia entre los dos elemen-tos afrontados es variable de acuerdo a la ubicación sobre el perímetro de los arcos ojivales superiores mientras más cerca están de la cúspide. Existe de todos modos un eje de simetría (rojo), un eje de orientación variable (lila), una línea base (amarilla) y ejes perpendiculares a la orientación (verdes). En el cuarto caso las bases de las pilastras de la ventana se desdoblan en los dos sentidos vertical y horizontal; por esta razón existen sendos ejes de simetría que permiten descomponer a la forma en cuatro partes idénticas, con un punto central en cuya circunferencia resultante se inscribe la base. En el cuarto caso la geometría fitoforme es mucho más compleja, sin embargo, puede resumirse en un solo eje simétrico de desdoblamiento vertical

Fuente: Elaboración propia, 2019

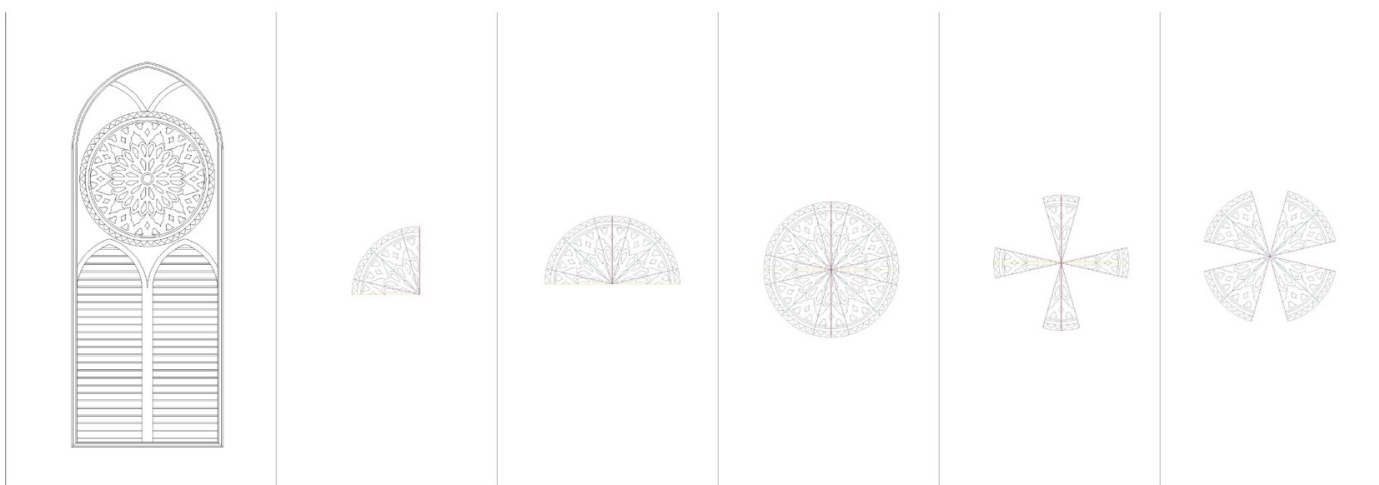

Anexo 2: Desarrollo geométrico de las formas existentes en los componentes de la ventana tipo 2. En este único caso de análisis, el rosetón en talla de madera tiene cuatro ejes de simetría diferentes (uno vertical amarillo, uno horizontal azul y dos transversales azules), que, al descomponer los pares de formas afrontadas y especulares, se puede dividir al rosetón en ocho partes agrupadas, solo idénticas de cuatro en cuatro, dando lugar a dos tipos de cruces, una gótica horizontal y otra pseudo-gótica transversal. Los ejes lilas no son de simetría sino de configuración y nos dan las áreas de división, de tal manera que resulten idénticas.

Fuente: Elaboración propia, 2019. 


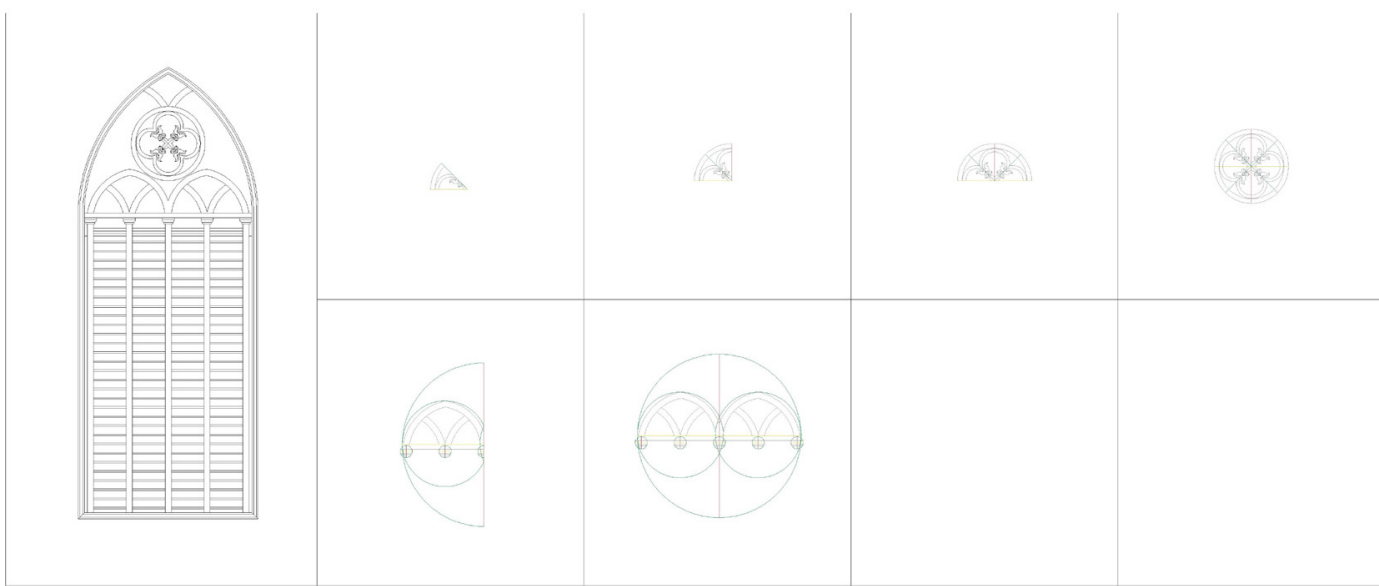

Anexo 3: Desarrollo geométrico de las formas existentes en los componentes de la ventana tipo 3. En el primer caso, el primer eje de desdoblamiento es un eje de simetría transversal (verde); al proyectar su contraparte a 45으, tenemos la primera cuarta parte de la forma. Un ulterior desdoblamiento en su eje vertical (rojo), nos lleva a su mitad y por último, un tercer desdoblamiento en su eje horizontal (amarillo) nos da la totalidad de la forma. En el segundo caso de análisis de desarrollo formal, las dos ojivas abiforadas tienen un solo eje de simetría vertical central (rojo) que a desdoblarse da la forma total; sin embargo, una línea base (amarilla) y las circunferencias (verdes) indican cómo se encuentran inscritos los arcos ojivales mayores, menores y los pseudo-capiteles como base de las ojivas. Nótese la relación perfecta de los dos círculos inscritos dentro del círculo mayor

Fuente: Elaboración propia, 2019.

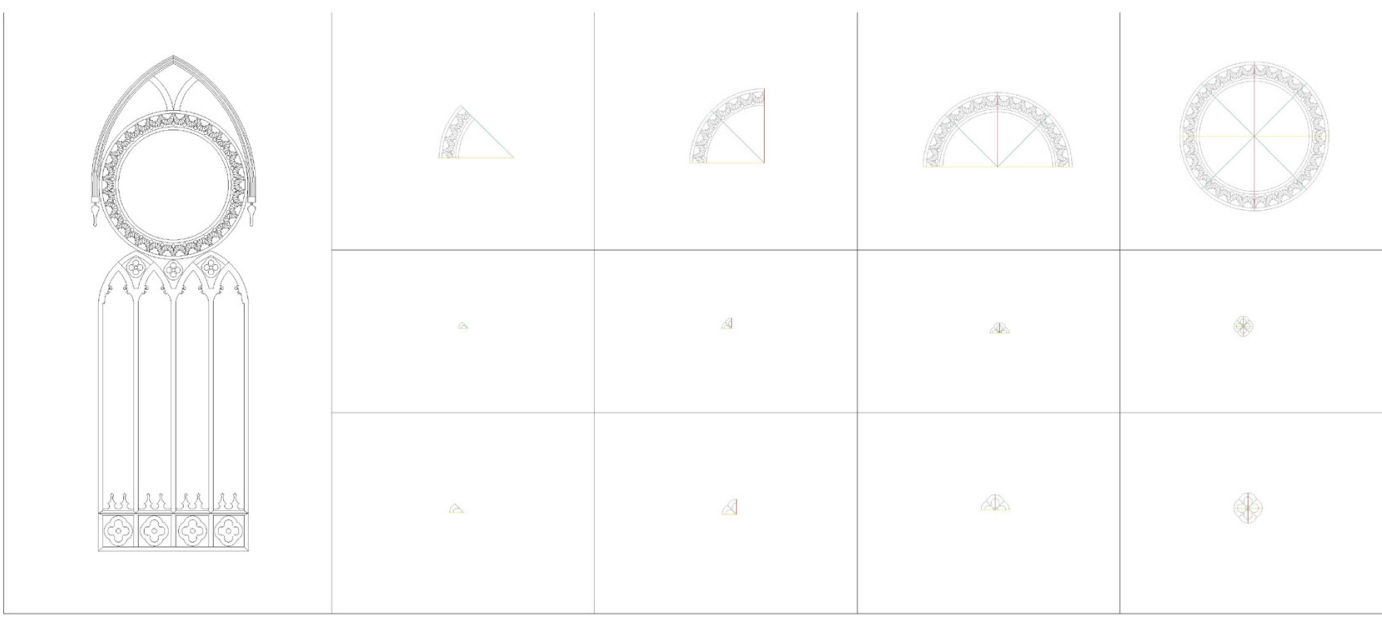

Anexo 4: Desarrollo geométrico de las formas existentes en los componentes de la ventana tipo 4. Tanto en el primer caso como en el segundo caso y tercer caso el primer eje de desdoblamiento es un eje de simetría transversal (verde). Esta primera parte es en realidad un octavo del rosetón. Al proyectar su contraparte a 45으, tenemos la primera cuarta parte de la forma. Un ulterior desdoblamiento en su eje vertical (rojo), nos lleva a su mitad y por último, un tercer desdoblamiento en su eje horizontal (amarillo) nos da la totalidad de la forma. Este tipo de desdoblamiento en ocho y cuatro partes es típico de los componentes de las ventanas de la segunda planta de la torre-campanario, donde se encuentra el reloj de la ciudad.

Fuente: Elaboración propia, 2019 


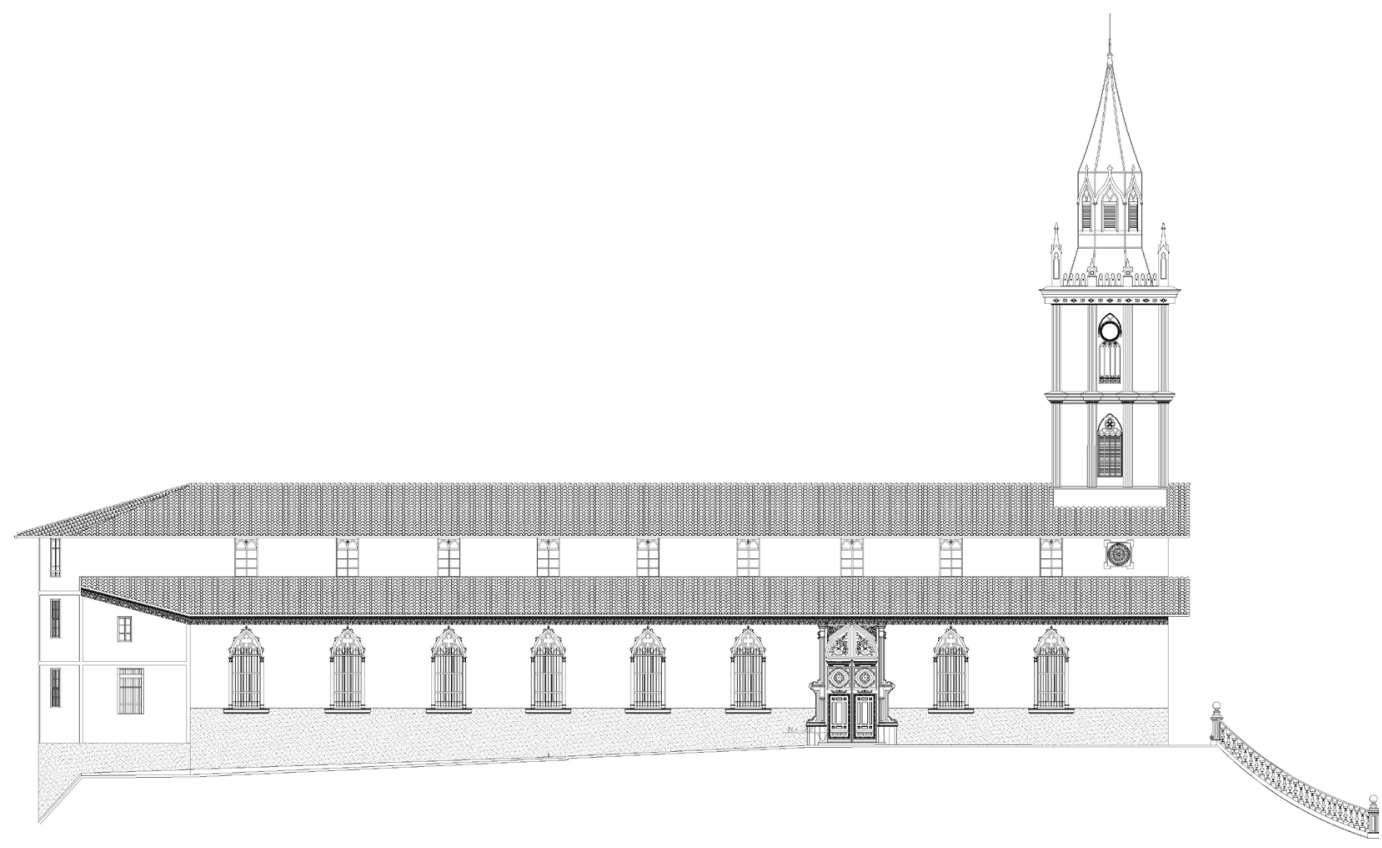

Anexo 5: Existen cinco ordenes con subdivisiones llamadas registros, en algunas de estas secciones. El primer orden cubre la distancia desde el piso hasta la altura de las naves laterales. Este primer orden se divide en cuatro registros: "A" (base champeada de color café a modo de antepecho), "B" (muro liso de color claro donde se encuentran emplazadas las ventanas), " $C$ " (cornisa de remate de las naves laterales) y " $\mathrm{D}$ " (altura proyectada de la cubierta de las naves laterales). El segundo orden define la altura del claristorio, o sea distancia que va desde la cumbrera de las naves laterales hasta la cumbrera de la nave central. Este segundo orden tiene tres registros: "E" (muro liso de color claro donde se encuentran las bíforas del claristorio, " $\mathrm{F}$ " (falso friso decorativo) y "G" (altura proyectada de la cubierta de la nave central). El tercer orden abarca la distancia desde la cúspide de la nave central hasta el friso de la primera planta de la torre-campanario. Este tercer orden se divide en dos registros " $\mathrm{H}$ " (muro con láminas de aluminio corrugado donde se emplazan las bíforas con ojiva) e "I" (cornisa que remata la primera planta de la torre-campanario). El cuarto orden se extiende verticalmente a lo largo de la segunda planta de la torre-campanario. Este cuarto orden también se divide en dos similares registros "J" (muro con láminas de aluminio corrugado donde se emplazan las cuadríforas ciegas con ojivas y los relojes de la torre-campanario) y " $K$ " (friso-cornisa que remata la segunda planta de la torrecampanario), y finalmente el quinto orden está ocupado por toda la altura de la linterna de la iglesia, que va desde el friso-cornisa de la segunda planta de la torre-campanario hasta la aguja de la linterna. Este último orden a su vez se subdivide en tres registros: "L" (altura proyectada del tramo piramidal truncado de sección octagonal que va desde el friso-cornisa de la segunda planta de la torre-campanario hasta el inicio del siguiente tramo), " $\mathrm{M}$ " (altura recta del tramo de sección octagonal que va desde la cúspide del registro "L" hasta la base de la cúspide), y finalmente "N" (altura proyectada del tramo piramidal no truncado de sección octagonal que va desde la cúspide del registro. Fuente: Elaboración propia, 2019. 


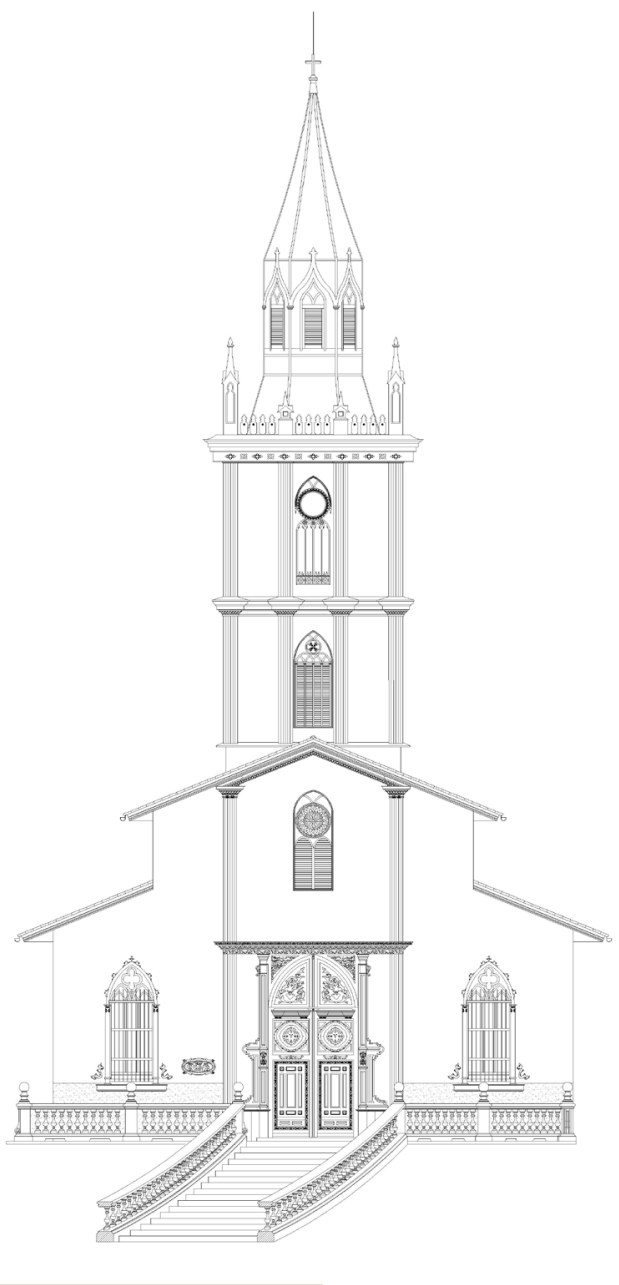

Anexo 6: Aquí se puede reconocer, del primer orden externo, el lado anterior (fachada baja y alta frontal o principal que da hacia la escalinata que comunica la calle principal de la ciudad, calle Bolívar, con el ingreso principal de la iglesia y el lado posterior (fachada baja posterior) que está compuesto por cuatro secciones que juntas dan la impresión de una curva y juntas forman el ábside le la iglesia. En el segundo orden externo se aprecia el lado anterior (fachada alta frontal), aquel que da hacia la escalinata y que asimismo comunica la calle principal de la ciudad, calle Bolívar, con el ingreso principal de la iglesia. No se debe considerar como continuidad de la misma envolvente en sus tres lados anteriores. En otras palabras, este último segmento de la envolvente no existe ya que es absorbido por el lado anterior de la envolvente del primer orden externo, el cual se prolonga y se fusiona con el lado anterior de la envolvente del segundo orden externo, para así formar un solo orden externo en dos alturas (fachada baja frontal y fachada alta frontal). En este segundo orden se aprecia también el lado posterior (fachada alta posterior) que está compuesto por dos tramos de muro, los cuales están en correspondencia con el 2 do y $3 e r$ tramo de muro del primer orden externo, y conjuntamente forman la altura total del ábside le la iglesia. En el tercer orden externo, se ven los lados anterior y posterior (fachada anterior y posterior de la primera planta de la torre-campanario respectivamente) que tienen la misma altura externa que aquellas de su lados derecho e izquierdo (fachada lateral izquierda y lateral derecha de la primera planta de la torre-campanario respectivamente). En el cuarto orden externo, se reconocen los lados anterior y posterior (fachada anterior y posterior de la segunda planta de la torre-campanario respectivamente) que arrancan desde el cubreaguas de la cornisa del tercer orden externo y terminan en el cubreaguas que remata la cornisa de este cuarto orden externo. El quinto y último orden externo está constituido por los ocho lados de la linterna de sección octagonal que van desde su arranque al nivel del friso-cornisa del cuarto orden externo (segunda planta de la torrecampanario) hasta el pináculo rematado por la cruz cristiana mirando hacia el noroeste.

Fuente: Elaboración propia, 2019 


\section{Referencias bibliográficas}

Aguirre, K. (2014). Diagnóstico de Patrimonios y Atractivos del Cantón Zaruma Provincia de el Oro para su promoción turística enfocada en el turismo cultura (Tesis de pregrado). Universidad Católica de Santiago de Guayaquil, Guayaquil.

Beigbeder, O. (2009). Léxico de los símbolos. St. Léger Vauban, Francia: Zodiaque. Traducción italiana: Lessico dei Simboli Medievali. Milán, Italia: Jaca Book.

Bertocci, S. y Bini, M. (2012). Manual de relevamiento arquitectónico y urbano. Colección Arquitectura. Florencia, Italia: CittàStudi.

Biedermann, H. (2004). Knaurs Lexicon der Symbole Droemersche Verlagsanstalt Th. Knaur Nachf: München, 1989. Traducción italiana: Enciclopedia dei Simboli. Italia: Garzanti Editore.

Cairo, G. (2008). Diccionario razonado de símbolos. Bolonia, Italia: Forni.

Cecchini, N. (1998). Diccionario sinóptico de iconología. Bolonia, Italia: Pàtron.

Champeaux de, G. y Sterckx S. (1980). Introducción al mundo de los símbolos. Paris, Francia: sin editorial.

Chevalier, J. y Gheerbrant, A. (1997). Diccionario de símbolos. París, Francia: Ediciones Robert Laffont S. A. y Ediciones Júpiter, 1969. Traducción italiana: Dizionario dei simboli-miti sogni costumi gesti forme figure colori numeri. Milán, Italia: RCS Rizzoli Libri S. p. A.

Cooper, J. C. (2012). Diccionario de símbolos: Diccionario ilustrado de símbolos tradicionales de todo el mundo. Pádova, Italia: F. Muzzio.

Docci, M. y Maestri, D. (2009). Manual de relevamiento arquitectónico y urbano. Roma, Italia: Laterza.

Feuerstein, G. (2001). El lenguaje espiritual de los números. Milán, Italia: Armenia.

Genovese, R. (1994). Técnicas para el restauro. Notas sobre el relevamiento fotogramétrico. Colección Restauro. Roma, Italia: Edizioni Scientifiche Italiane.

Jung, C. G. (1991). El hombre y sus símbolos. Milán, Italia: Longanesi.

Klange, B. (2001). I Mosaici della Scarsella del San Giovanni a Firenze: I'Iconografia. En Commentari, anno XXVI, pp. 248-257. Roma, Italia: De Luca editore.

Konsminsky, I. (1998). Los números mágicos. Milán, Italia: Garzanti-Vallardi.

Mallinger, J. (2008). Pitágoras y los misterios. Roma, Italia: Atanòr S. r. I.
Poma, V. (1992). Documentos de Zaruma: Historiografía Orense. Colección Libros de Historia: "Nuestra Tierra". Machala, Ecuador: Agencia Editorial P\&C DOS MIL 3.

Redazione Garzanti a cura di Edigeo. (2013). Dizionario Enciclopedico di Arti, Scienze, Tecniche, Lettere, Filosofia, Storia, Geografia, Diritto Economia. Milán, Italia: Zanichelli Editori s.p.a.

Rees, E. (1994). Símbolos cristianos y raíces antiguas. Cinisello Balsamo, Italia: San Paolo.

Reyes, Á. y Valarezo, A. (2011). Hilos del tiempo: relatos y testimonios de "El Toro" Alfredo Valarezo Zambrano. Zaruma, Ecuador: Ediciones Concejo Nacional de Cultura.

Romero, A. (2011). Imágenes de Zaruma: Fotografías de Ramón Jijón y León Jiménez. Zaruma, Ecuador: Ediciones Concejo Nacional de Cultura.

Ronchetti, G. (2004). Diccionario ilustrado de símbolos: Símbolos, emblemas, atributos, alegorías, imágenes de los dioses, etc. Milán, Italia: Hoepli.

Urech, É. (2001). Diccionario de símbolos cristianos. Roma, Italia: Edizioni Mediterranee. 